\title{
BMJ Open Association between early bronchiolitis and the development of childhood asthma: a meta-analysis
}

\author{
Guizuo Wang, ${ }^{1}$ Dong Han, ${ }^{1}$ Zhengdong Jiang, ${ }^{2}$ Manxiang Li, ${ }^{3}$ Shumei Yang, ${ }^{1}$ \\ Lu Liu (1D) 1
}

To cite: Wang G, Han D, Jiang Z, et al. Association between early bronchiolitis and the development of childhood asthma: a meta-analysis. BMJ Open 2021;11:e043956. doi:10.1136/ bmjopen-2020-043956

- Prepublication history and additional supplemental material for this paper are available online. To view these files, please visit the journal online (http://dx.doi.org/10.1136/ bmjopen-2020-043956).

Received 18 August 2020 Accepted 05 May 2021

Check for updates

(c) Author(s) (or their employer(s)) 2021. Re-use permitted under CC BY-NC. No commercial re-use. See rights and permissions. Published by BMJ.

${ }^{1}$ Department of Respiratory and Critical Care Medicine, Shaanxi Provincial People's Hospital,

Xi'an, Shaanxi, China

${ }^{2}$ Department of General Surgery, The First Affiliated Hospital of Xi'an Jiaotong University, Xi'an, Shaanxi, China

${ }^{3}$ Department of Respiratory and Critical Care Medicine, The First Affiliated Hospital of Xi'an Jiaotong University, Xi'an, Shaanxi, China

Correspondence to

Dr Lu Liu; liulu290@126.com

\section{ABSTRACT}

Objective Early life bronchiolitis has been hypothesised to be associated with the subsequent risk of persistent wheezing or asthma. However, the link remains controversial. The objective of our study was to evaluate the association between bronchiolitis before 2 years of age and the late-onset wheezing/asthma.

Design Systematic review and meta-analysis.

Methods PubMed, Embase and Web of Science databases were systematically searched for studies published between 1955 and January 2020. Meanwhile, we also checked through the reference lists of relevant articles to see whether these references included reports of other studies that might be eligible for the review. Cohort and case-control studies assessing the association between early-life bronchiolitis and late-onset wheezing/asthma were included in this meta-analysis. Data were extracted by two independent reviewers. Results were pooled using a random-effects model or fixed-effects model according to the heterogeneity among studies.

Results 32 original articles with 292844 participants, which met the criteria, were included in this meta-analysis. Bronchiolitis before 2 years of age was associated with an increased risk of subsequent wheezing/asthma (relative risk $=2.46,95 \% \mathrm{Cl} 2.14$ to 2.82, $\mathrm{p}<0.001$ ). After categorising studies into different groups based on age at the end of follow-up, geographical region and study quality, the association still remained significant.

Conclusions The meta-analysis indicates an association between bronchiolitis before 2 years of age and the wheezing/asthma in later life. Well-designed and highly standardised prospective studies that better address bias due to potential confounding factors are needed to validate the risk identified in our meta-analysis.

PROSPERO registration number

CRD42018089453.

\section{INTRODUCTION}

Asthma is one of the most common chronic, noncommunicable respiratory diseases and its prevalence has increased in the world, leading to high-cost emergency care and hospitalisations, ${ }^{1}$ with a substantial negative impact on quality of life among children and adults. ${ }^{2}$ The aetiology of asthma is complex, involving the interactions of multiple environmental and genetic stimuli. ${ }^{3}$ There have

\section{Strengths and limitations of this study}

This meta-analysis aimed to examine whether early bronchiolitis increased the risk of childhood wheezing/asthma is of great significance.

- All the studies included had moderate to high qualities according to the Newcastle-0ttawa Scale.

- There was substantial heterogeneity in the pooled data even after subgroup analyses.

- Only published studies with sufficient data were included, so the possibility of publication bias cannot be completely ruled out.

been many meta-analyses trying to identify risk factors for asthma. Exposure to smoke, ${ }^{4}$ male gender, atopic dermatitis, family history of asthma, history of wheezing and serum IgE level $\geq 60 \mathrm{kU} / \mathrm{L}$ or having specific IgE are found to be positively associated with developing asthma. ${ }^{5}$ Breastfeeding $^{6}$ and exposure to cats and $\operatorname{logs}^{7}$ seem to play protective roles in the development of asthma. However, the associations between high adherence of the Mediterranean diet during pregnancy and childhood $^{8}$ and swing attendance during childhood $^{9}$ with asthma are still unclear.

Bronchiolitis is a lower respiratory tract infection in children younger than 2 years old characterised by respiratory distress, wheezing and crackles. ${ }^{10}$ It is primarily caused by viral infections, particularly respiratory syncytial virus (RSV), which is responsible for $70 \%$ of episodes of bronchiolitis. ${ }^{11}$ Other viruses, such as rhinovirus, human metapneumovirus, influenza A and B viruses, parainfluenza virus, adenovirus, papillomavirus and bocavirus, have also been implicated. ${ }^{12}$ Bronchiolitis is a major public health problem worldwide, the prevalence of bronchiolitis is $20 \%-30 \%$ in the first year and $10 \%-20 \%$ in the second year of life. ${ }^{13}$ It is also the leading cause of hospitalisation in infants and young children. Approximately, $1 \%-3 \%$ of infants 
need hospitalisation for bronchiolitis-most commonly those aged $<6$ months. ${ }^{14}$

Although numerous clinical studies have been conducted since the 1950s to investigate the relationship between bronchiolitis and subsequent persistent wheezing or asthma, the link remains controversial. ${ }^{15-18}$

The demonstration of a relation between bronchiolitis and the subsequent wheezing/asthma, and a better understanding of the association may be important for the prevention and treatment of asthma. A previous meta-analysis has shown an association between infant RSV hospitalisation and asthma/wheezing sequelae, ${ }^{19}$ but it did not consider other viruses causing bronchiolitis. Therefore, we have conducted a systematic review and meta-analysis of the existing available evidence.

\section{METHODS}

This study was conducted according to the Preferred Reporting Items for Systematic Reviews and Meta-Analyses guidelines. The protocol was registered in PROSPERO.

\section{Search strategy}

We systematically searched the PubMed, Embase and Web of Science to identify available English language articles published between 1955 and January 2020. Using the following search terms: (infant OR child OR children) AND bronchiolitis AND (wheezing OR asthma). The research strategy for each database was established with the help of a research librarian (see online supplemental table S1). Meanwhile, we also checked through the reference lists of relevant articles to see if these references included reports of other studies that might be eligible for the review.

\section{Inclusion and exclusion criteria}

Articles were selected for inclusion only if they meet all the following criteria: (1) cohort study or case-control study type, (2) the diagnosis of bronchiolitis was made by a physician and the maximum age when diagnosed was $\leq 2$ years, (3) outcome of interest was wheezing/asthma (diagnosed by a physician or reported by the parents or retrieved from medical insurance databases), (4) measures of association (OR, HR or relative risk (RR)) and their $95 \%$ CI or data allowing for computation of summary measures are provided. Results at multiple follow-up times from a same study will be correlated, which will result in SEs (corresponding 95\% CIs) that do not reflect the true variability. Therefore, if a study had several periods of follow-up, we used the values from the longest follow-up. Studies were excluded if they did not meet these inclusion criteria. Unpublished or grey literature data (eg, in terms of conference abstracts, dissertations or editorials) were not considered. The selection of the studies was by two reviewers independently and discussion was needed to resolve the discrepancies, if needed, by adjudication from a third reviewer.

\section{Data extraction and quality assessment}

Data were extracted by two independent reviewers and, in the case of discrepancies, the final decision was made by a third investigator. From each eligible article, we recorded: first author, publication year, original country where the study was conducted, study type, number of participants, age when diagnosed of bronchiolitis, bronchiolitis infection virus, outcome, age at the end of follow-up and the effect estimate (95\% CI). We selected the outcome based on the following criteria if a study reported several potential outcomes of interest (eg, asthma, wheezing and recurrent wheezing): (1) diagnosis by a physician was selected over parental assessment, (2) current respiratory status or respiratory status in the past 12 months was selected over cumulative outcome, (3) asthma was selected over wheezing. ${ }^{20}$ The quality of each study was independently assessed by two reviewers according to the NewcastleOttawa Scale (NOS).$^{21}$ A study awarded a score of 0-3, 4-6 or 7-9 was considered as a low, moderate or highquality study, respectively. If there are discrepancies, they will be resolved by consensus and discussion.

\section{Statistical methods}

We extracted the association (OR or RR or HR) and their $95 \%$ CI or derived by using data from the original studies (unadjusted $\mathrm{RR}=\mathrm{P}_{1} / \mathrm{P}_{0}, \mathrm{P}_{1}$ indicates the incidence of the outcome of interest in the exposed group and $\mathrm{P}_{0}$ in the nonexposed group). ${ }^{22}$ It is not recommended to combine HRs with RRs and ORs in a meta-analysis, as HRs represent instantaneous risk over the study time period, whereas RRs and ORs estimate risk/odds at a fixed time point. ${ }^{23}$ The ORs were transformed into RRs using the formula $\mathrm{RR}=\mathrm{OR} /($ (1$\left.\left.\mathrm{P}_{0}\right)\left(\mathrm{P}_{0} \times \mathrm{OR}\right)\right) .{ }^{22} \mathrm{HRs}$ and RRs (or RRs derived from ORs) should be presented in separate meta-analyses. Additionally, the transformation from ORs to RRs has some limitations and may underestimate the variance of the RRs derived from the ORs. ${ }^{24}{ }^{25}$ Therefore, we conducted a sensitivity analysis that excluded the studies where outcome was transformed. We also compared the results applying the Miettinen testbased approach for calculating the variance of the natural logarithm of the RR (lnRR; variance $\ln R R=-$ variance $\operatorname{lnOR} \times(\ln R R / \operatorname{lnOR})) .{ }^{26}$

The statistical analysis was done with Stata V.12.0 (Stata Corp, College Station, Texas, USA). We used the 'metan' command in Stata to pool the lnRR/ $\operatorname{lnHR}$. Forest plots were used to visually assess the individual and pooled estimates with the corresponding 95\% CIs. In meta-analysis, the usual way of assessing whether a set of single studies is homogeneous is by means of the $Q$ statistics. However, the $Q$ statistic only informs meta-analysis about the presence versus the absence of heterogeneity, but does not report on the extent of such heterogeneity. Moreover, it has poor power to detect true heterogeneity among studies when the meta-analysis includes a small number of studies. $\mathrm{I}^{2}$ index is proposed to quantify the degree 


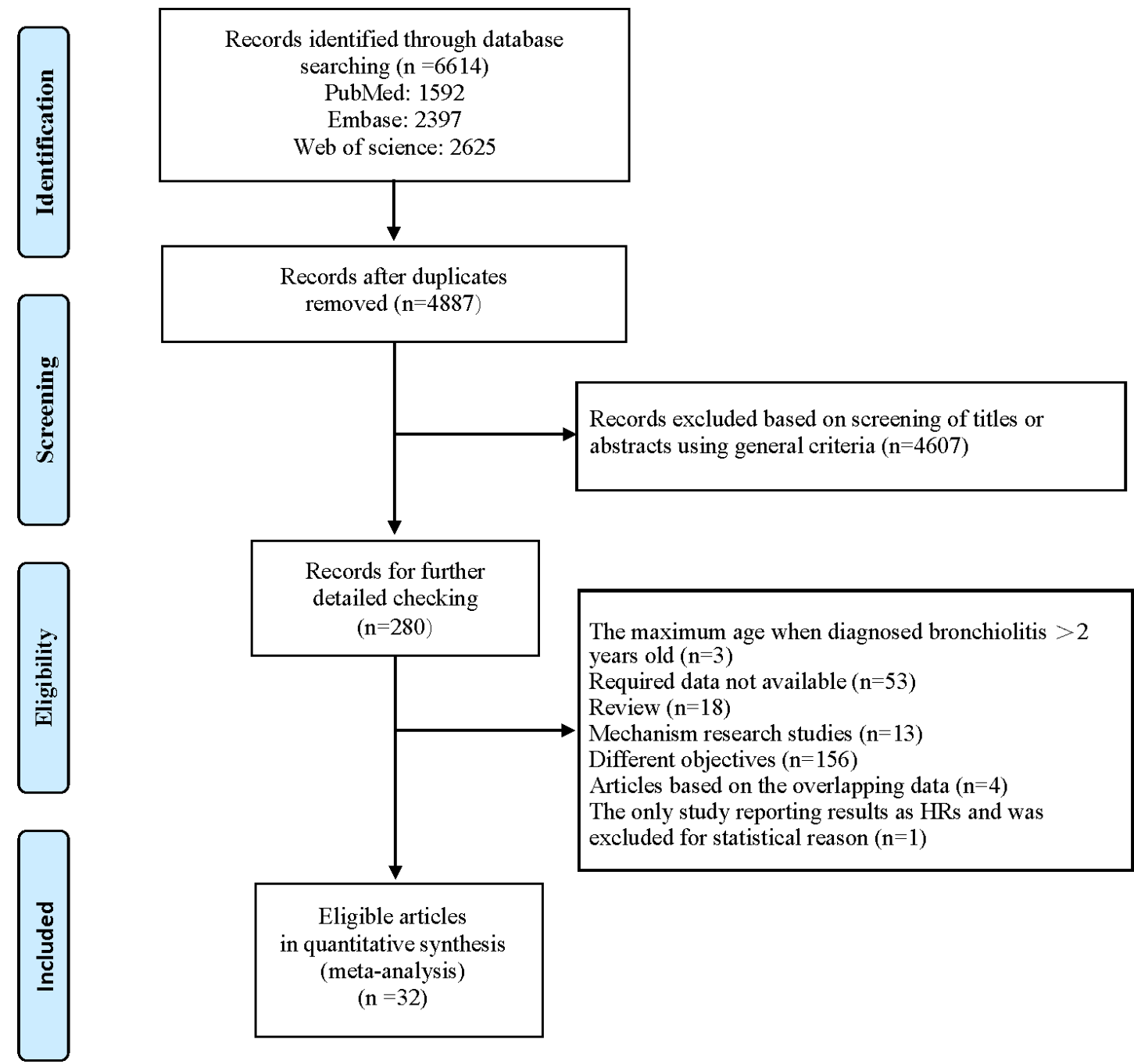

Figure 1 The flow diagram of identifying relevant studies.

of heterogeneity and considered as a complement to the $Q$ statistic, although it has the same problems of power with a small number of studies. ${ }^{27}$ Therefore, we used the $Q$ statistics (significance level of $p<0.10$ ) and $\mathrm{I}^{2}$ statistics ( $>50 \%$ was usually judged to significant inconsistency) to comprehensively evaluate betweenstudy heterogeneity. ${ }^{28}$ A fixed-effects model was used when heterogeneity between studies was not significant, while a random-effects model was adopted. Analyses were stratified by age at the end of follow-up $(<10$ years and $\geq 10$ years), geographical region (Europe, North America, South America and Asia) and study quality (NOS score 4-6, moderate quality and NOS score $7-9$, high quality). We chose 10 years old as the cut-off in the age stratification analysis for the following reasons: Sears $e t a l^{29}$ and McGeachie $e t a l^{30}$ indicate that children presenting with abnormal lung function after the age of 10 years have lower lung function in adulthood; Sousa et $a l^{31}$ show that onset of fixed airflow obstruction (FAO) starts at 10 years of age. After 10 years of age, the FEV1/FVC ratio is lower in the FAO group than in the non-FAO group. Potential publication bias was assessed by using funnel plot and Begg's and Egger's tests, and $\mathrm{p}<0.05$ was considered significant. $^{3233}$

\section{Patient and public involvement}

Patients and the public were not involved in this review.

\section{RESULTS}

\section{Study characteristics}

A total of 6614 citations were identified: 1592 from PubMed, 2397 from Embase and 2625 from Web of Science. Of these, 1727 were excluded for duplicates and 4607 were excluded after the first screening based on abstracts or titles, leaving 280 articles for full-text review. The study by Lin H-W and Lin S-C ${ }^{34}$ has shown that the acute bronchiolitis in young children younger than 2 years old is correlated with the later development of asthma. It was the only study reporting results as HRs after full-text review. However, one study should not result in any model tests of significance and allow us to perform a separate meta-analysis. So, we did not include it in the pooled analyses and excluded it. Two articles were published by the same author in the 
\begin{tabular}{l|lll}
$\mathbf{2}$ & & & \\
$\mathbf{Z}$ & ก & 1 & 0
\end{tabular}

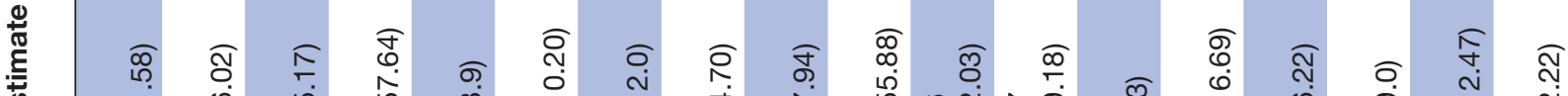
ङ





至





¿

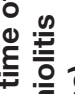

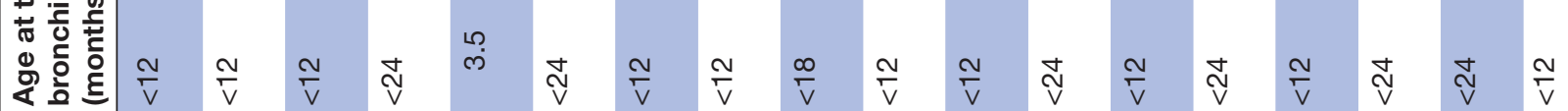

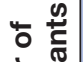

至

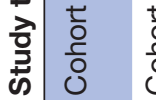

$\frac{1}{0}$
$\frac{1}{0}$
0

$\begin{array}{lll}\frac{1}{0} & \frac{t}{0} \\ \frac{t}{0} & \frac{1}{0} \\ 0 & 0\end{array}$

$\begin{array}{lll}0 & \frac{1}{0} & \frac{1}{0} \\ 0 & \frac{1}{0} & \frac{0}{0} \\ 0 & \frac{0}{0} & \frac{0}{0} \\ 0 & 0 & 0\end{array}$

$\begin{array}{ll}\frac{1}{2} & \frac{1}{0} \\ \frac{1}{0} & 0 \\ \frac{1}{0} & \frac{1}{0}\end{array}$

$\begin{array}{lllllll}\frac{t}{0} & \frac{t}{0} & \frac{t}{0} & \frac{t}{0} & \frac{t}{0} & \frac{t}{0} & \frac{t}{0} \\ \frac{\tau}{0} & \frac{\tau}{0} & \frac{\tau}{0} & \frac{\tau}{0} & \frac{\tau}{0} & \frac{\tau}{0} & \frac{\tau}{0} \\ 0 & 0 & 0 & 0 & 0 & 0 & 0\end{array}$

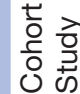

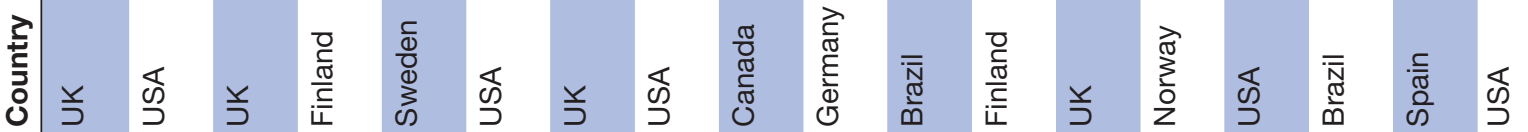
ฮั

竞 㐫 


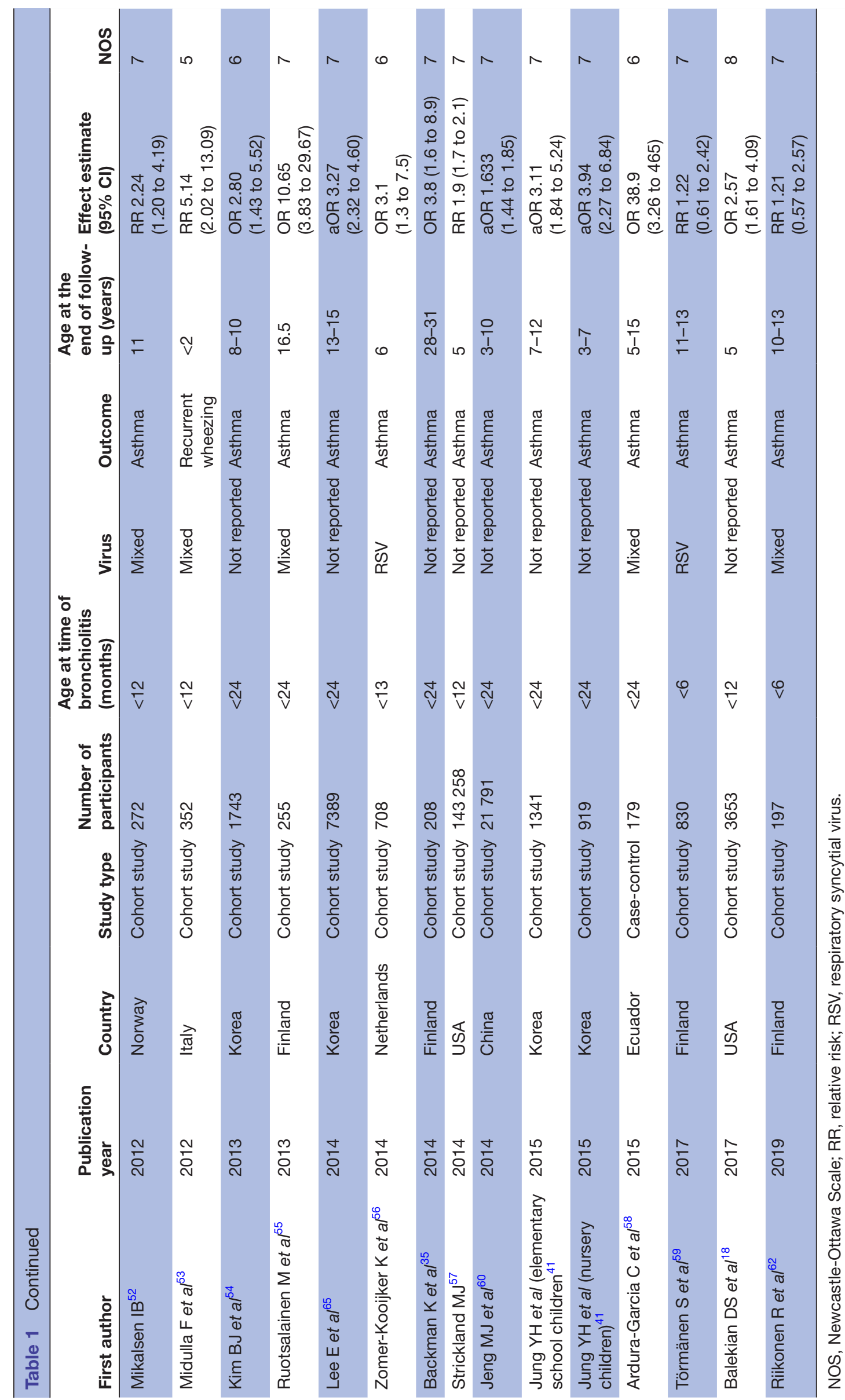




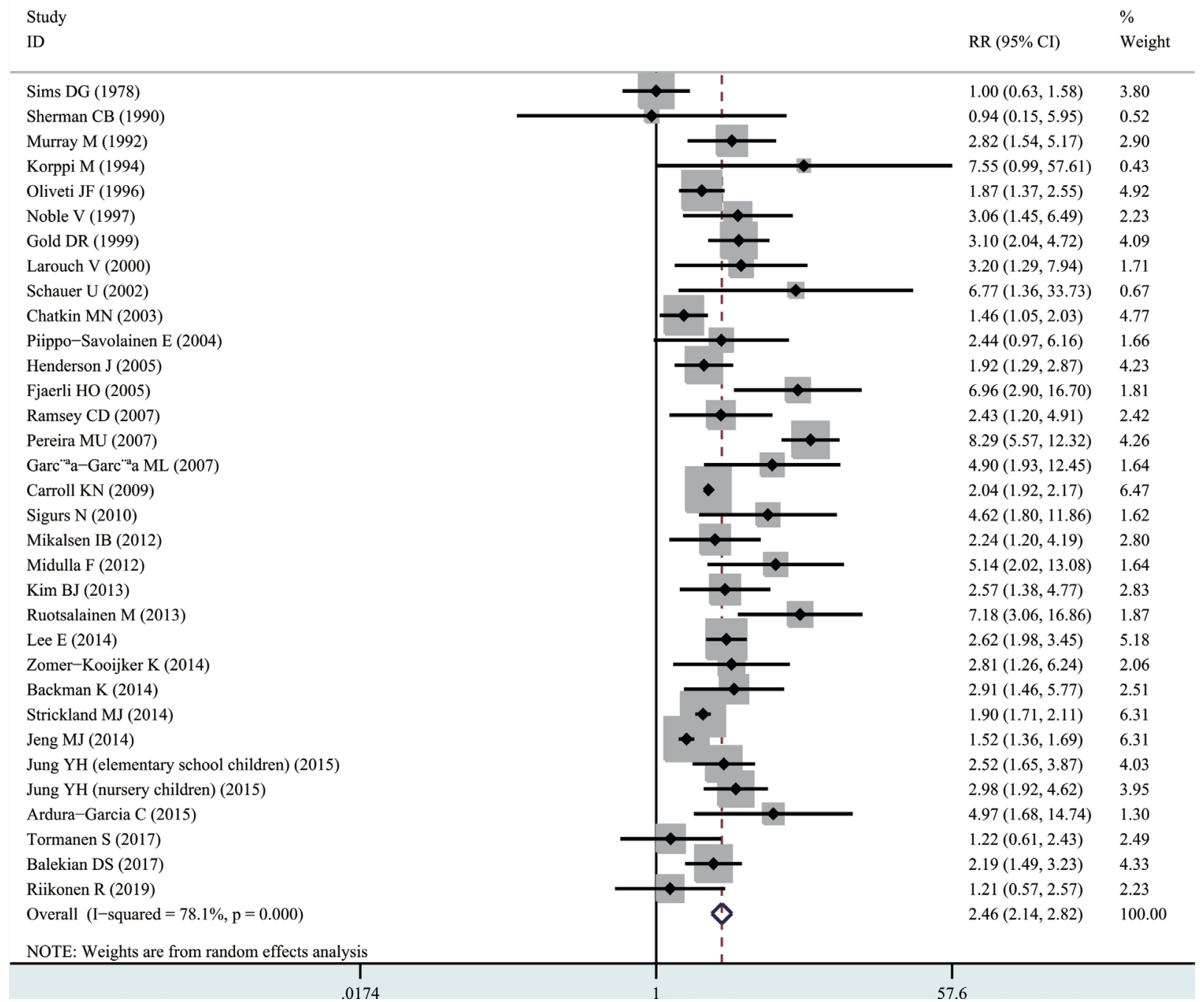

Figure 2 Forest plot of the overall association between bronchiolitis before 2 years of age and the subsequent development of wheezing/asthma.

same year and reported the results of a same cohort study, ${ }^{35} 36$ but with different objectives. We avoided duplicate inclusion of data by selecting only the more complete article. ${ }^{35}$ Additionally, four articles reported the results of a same longitudinal cohort study (Sigurs $e t a l^{37-40}$ ) with different lengths of follow-up period, we only included the one with longest follow-up according to the inclusion criteria. Finally, 32 articles (33 studies, one article included two independent cohort studies $)^{41}$ were eligible and included in our meta-analysis ${ }^{15-18} 343537$ 41-66 (figure 1). Among these studies, two were case-control studies, ${ }^{43} 5831$ were cohort studies. ${ }^{15-18} 343537414244-5759-66$ The main characteristics of the included studies are summarised in table 1 .

\section{Quality assessment}

All included studies were assessed by NOS and their score ranged from 5 to 8 , suggesting that the methodological quality was acceptable. The details of NOS assessment for each enrolled study are shown in online supplemental table S2 and S3.

\section{Quantitative synthesis}

Significant heterogeneity among studies was present $\left(\mathrm{I}^{2}=78.1 \%, \mathrm{p}<0.001\right)$, and thus a random-effects model was performed overall analysis. The combined results demonstrated that bronchiolitis before 2 years of age was associated with increased risk of wheezing/asthma $(\mathrm{RR}=2.46,95 \%$ CI 2.14 to $2.82, \mathrm{p}<0.001$; figure 2$)$. We further evaluate whether the association between bronchiolitis and development of wheezing/asthma would change with age. Significant heterogeneity was identified ( $<10$ years, $\mathrm{I}^{2}=82.5 \%, \mathrm{p}<0.001 ; \geq 10$ years, $\left.\mathrm{I}^{2}=49.8 \%, \mathrm{p}=0.043\right)$, and thus a random-effects model was used. The association still remained significant in $<10$ years $(\mathrm{RR}=2.40,95 \%$ CI 2.04 to $2.82, \mathrm{p}<0.001)$ and $\geq 10$ years $(R R=2.54,95 \%$ CI 1.84 to $3.50, p<0.001$, figure 3 ). When stratified analysis was conducted by geographical region, the association still remained significant in Europe ( $\mathrm{RR}=2.78,95 \%$ CI 2.04 to 3.79, $\mathrm{p}<0.001)$, North America ( $R R=2.02,95 \%$ CI 1.89 to 2.16, $\mathrm{p}<0.001)$, South America ( $R R=3.85,95 \%$ CI 1.02 to $14.52, \mathrm{p}<0.05)$ and Asia $(\mathrm{RR}=2.31,95 \%$ CI 1.63 to 


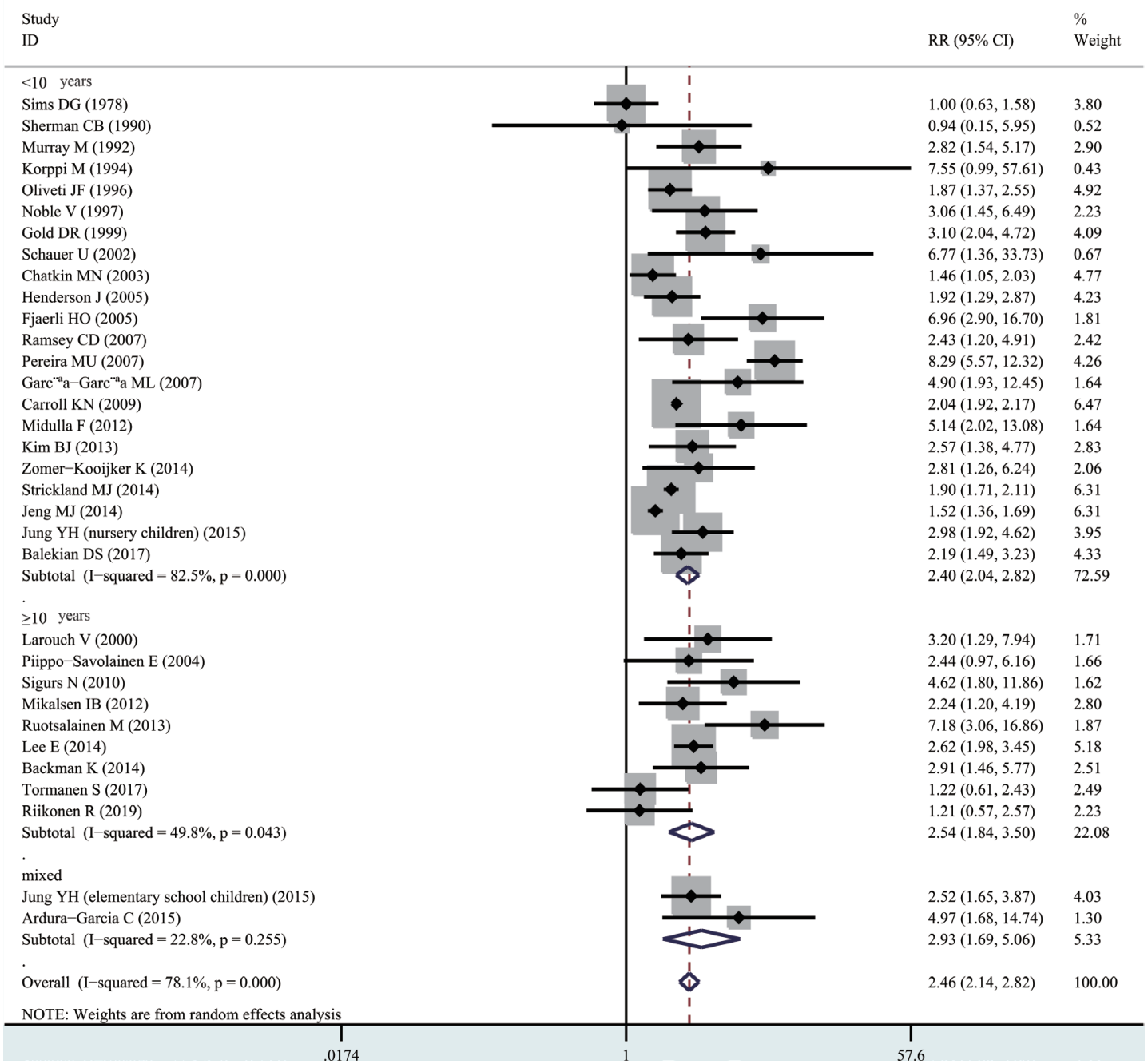

Figure 3 Forest plot of the association between bronchiolitis before 2 years of age and the subsequent development of wheezing/asthma, stratified by age at the end of follow-up.

3.28, $\mathrm{p}<0.001$; figure 4). In subgroup analysis by study quality, the significant association was identified in both moderate quality ( $\mathrm{RR}=3.16,95 \%$ CI 2.12 to 4.70 , $\mathrm{p}<0.001)$ and high quality $(\mathrm{RR}=2.15,95 \%$ CI 1.88 to $2.46, \mathrm{p}<0.001$ ) (figure 5).

\section{Sensitivity and publication bias analysis}

The sensitivity analysis that excluded all studies for which the transformation of ORs to RRs was used, which showed a similar result with a pooled RR of 2.07 (95\% CI 1.74 to $2.45, \mathrm{p}<0.001)$. We used the funnel plot to assess the publication bias, and the result showed there was no obvious asymmetry (figure 6). Furthermore, Begg's and Egger's test showed there was no significant publication bias $(p>0.05)$.

\section{DISCUSSION}

\section{Principal findings}

This meta-analysis on 33 studies provided considerable evidence indicating the positive association between early-life bronchiolitis and the subsequent development of wheezing/asthma. Regnier and Huels ${ }^{19}$ have indicated that the association between RSV hospitalisation in infants and asthma/wheezing decreases with age at the end of follow-up. To assess whether this association between bronchiolitis and later onset of wheezing/asthma would also change with age, we conducted subgroup analysis based on age at the end of follow-up, and the association still remained significant in both $<10$ years old and $\geq 10$ years old. The reason for this difference may be due to the multiple viral respiratory pathogens involved in the enrolled studies.

\section{Mechanisms of bronchiolitis on wheezing/asthma}

Bronchiolitis is the most common acute lower respiratory tract infection in infants and the primary cause of hospitalisation in this age group. Recently, a growing number of studies have been conducted to explore the association between bronchiolitis and the development of subsequent wheezing and asthma. However, the results are inconclusive. ${ }^{15-18}$ Therefore, it is crucial to include all eligible studies and to assess the overall association. In this meta-analysis, 


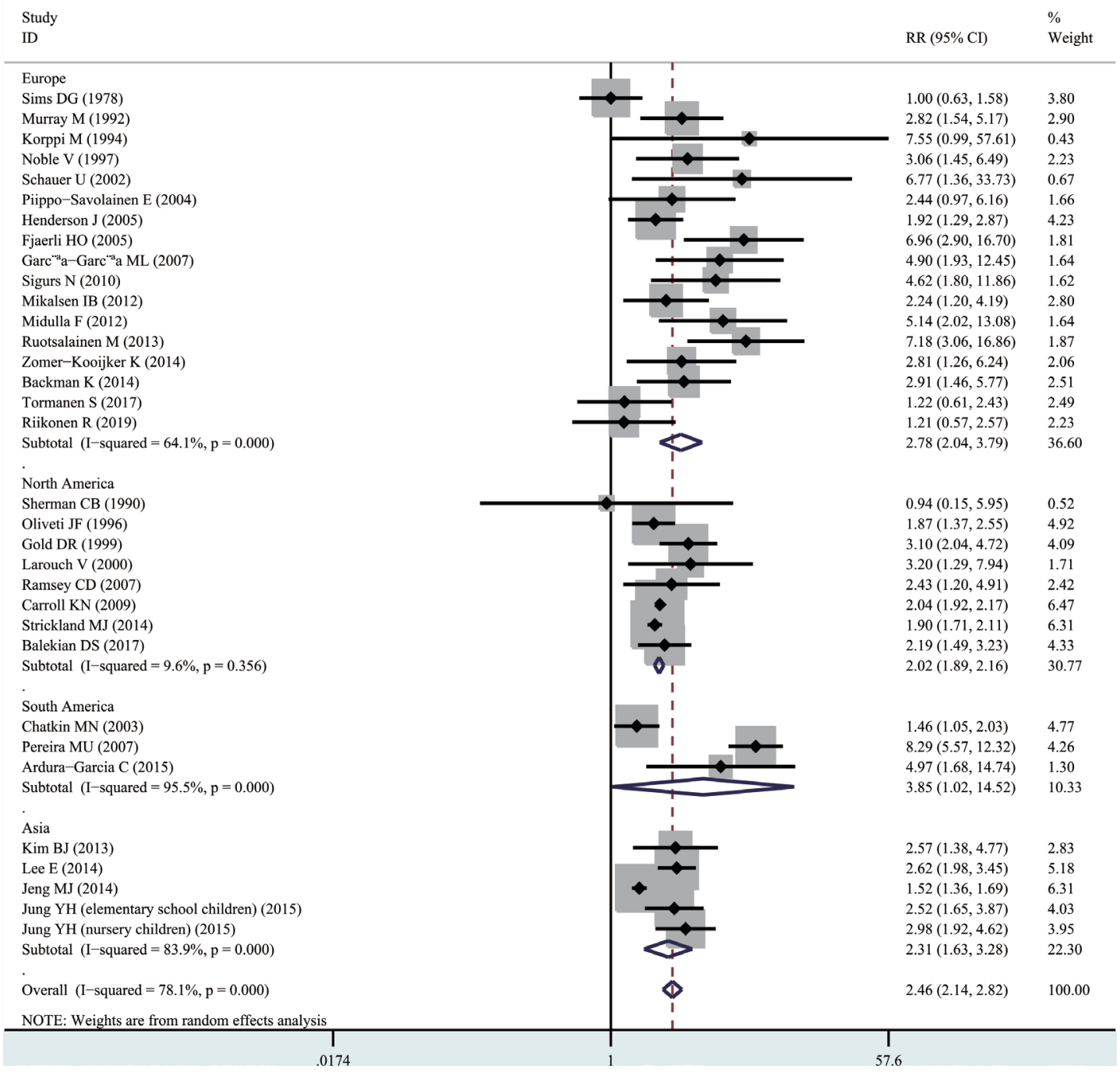

Figure 4 Forest plot of the association between bronchiolitis before 2 years of age and the subsequent development of wheezing/asthma, stratified by geographical region.

the combined results demonstrated the association between early bronchiolitis and the development of wheezing/asthma. In the first year of life, both the respiratory tract and the immune system mature rapidly, and it seems that postnatal development is affected by viral infection. A variety of potential biological mechanisms might underlie the association of bronchiolitis with wheezing/asthma. (1) Induction of inflammation typical of allergic asthma by $\mathrm{T}$ lymphocyte differentiation into Th2 $2^{67}$, (2) activation of Th17 cells and induction of IL-17 production. Activated Th17 cells regulate the production of other proinflammatory cytokines (IL-6, tumor necrosis factor (TNF)- $\alpha$, metalloproteinases etc), which may play important roles in the pathogenesis of asthma, ${ }^{68}$ (3) upregulation of IL-4 and downregulation of interferon (IFN)- $\gamma$ levels ${ }^{69}$ (4) induction of bronchial hyperactivity by inflammatory cells and sensory C-fibre neuropeptide, ${ }^{70}$ (5) imbalance of respiratory microbial communities. ${ }^{71}$

\section{Implications for practice}

Effective strategies against bronchiolitis could reduce the consequences of immune response to pathogens, thus reducing the risk of asthma. Unfortunately, despite the large public health burden, no effective treatment shortening the course or hastening the resolution of symptoms are available, other than supportive care in young children with bronchiolitis. ${ }^{72-74}$ It is mainly because of the wide variety of viruses involved in causing bronchiolitis and poor cross-protection between prior heterologous infections. RSV is considered as the main cause of bronchiolitis. There have been some studies exploring the effect of RSV prevention on respiratory morbidity. Scheltema et $a l^{75}$ indicate that RSV prevention in preterm infants is associated with a decrease in parent-reported wheeze at 6 years of age. Similar results have been reported by Mochizuki et $a l^{76}$ and Prais $e t a l .{ }^{77}$ However, the study conducted by Scheltema et al shows no effect of RSV prevention on current physician-diagnosed asthma at 


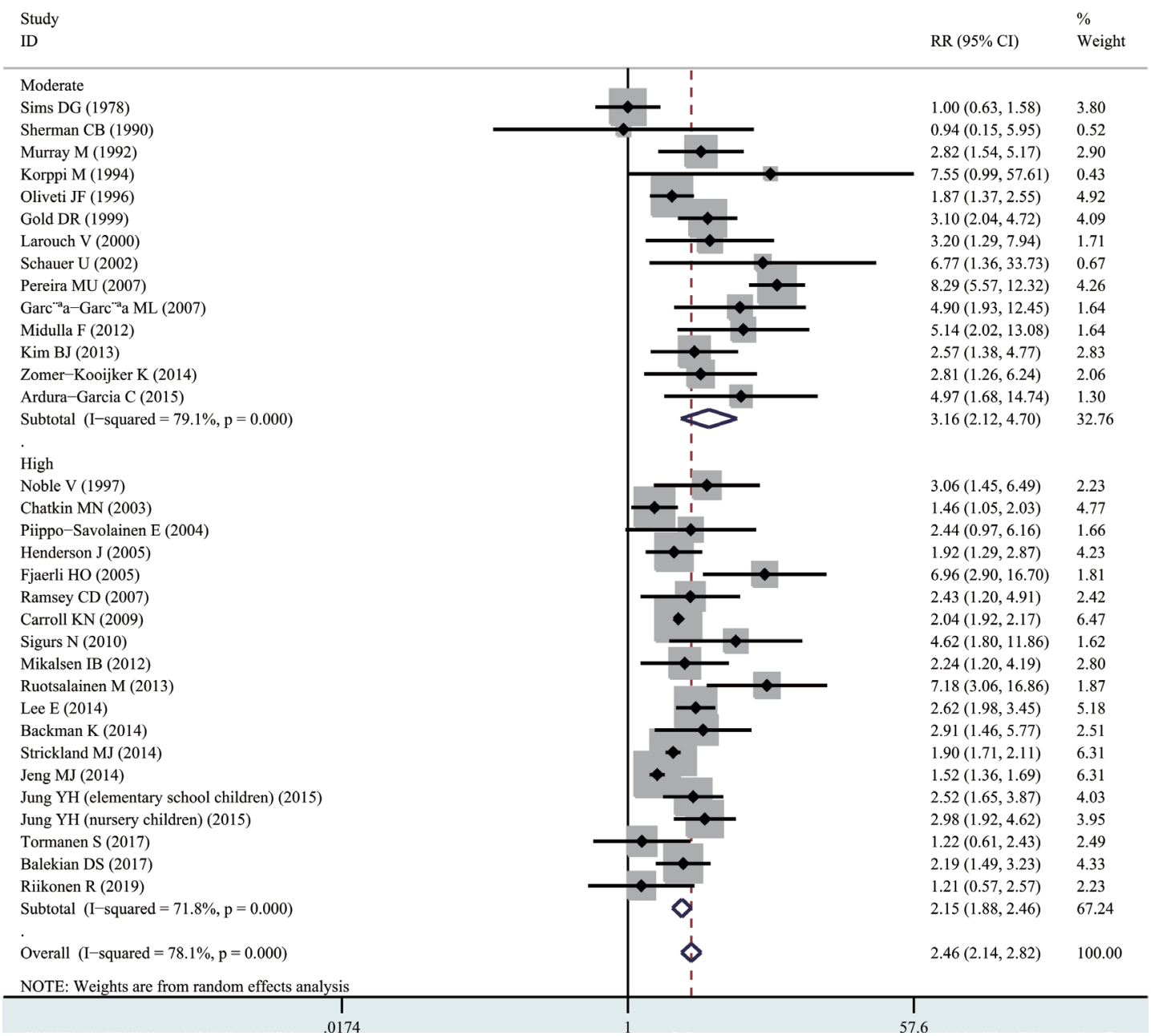

Figure 5 Forest plot of the association between bronchiolitis before 2 years of age and the subsequent development of wheezing/asthma, stratified by study quality.

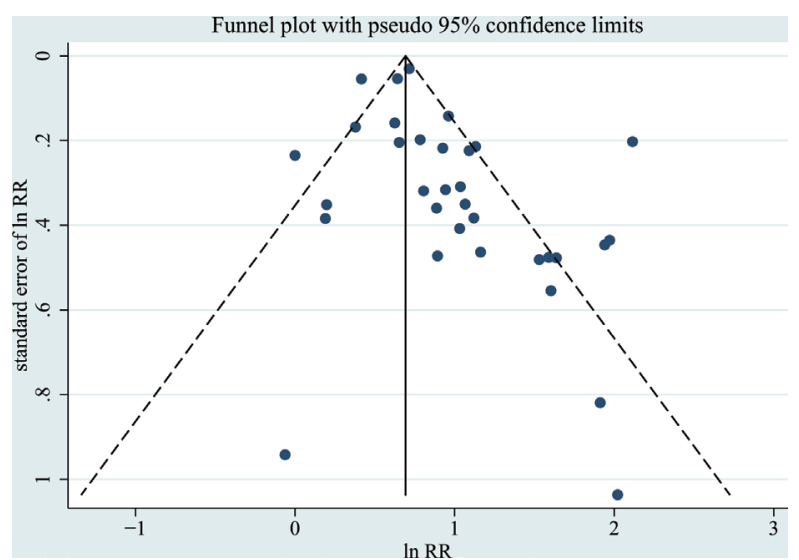

Figure 6 Funnel plot of publication bias for the association between bronchiolitis before 2 years of age and the subsequent development of wheezing/asthma. The horizontal axis represents $\ln R R$ and the vertical axis means the SE of InRR. Vertical line and sloping lines in funnel plot represent summary RR and expected $95 \% \mathrm{Cl}$ for a given SE, respectively. $R R$, relative risk. age of 6 years. A randomised controlled trial in term native American infants using motavizumab for RSV prophylaxis also indicates no effect of RSV prevention on medically attended wheeze up to age of 3 years. ${ }^{78}$ Two possible explanations exist for the differences between parent-reported and physician-diagnosed asthma. First, information bias might have occurred. Second, asthma symptoms might have not been severe enough to warrant a doctor's visit. In further studies, we should consider combining subjective outcomes (such as physician-confirmed asthma symptoms and patient-reported outcomes) with objective lung function measurements to minimise bias or exploring the effect of prevention of other important pathogens of bronchiolitis on asthma.

\section{Limitations}

There are some limitations to note. (1) The children with wheezing in the early stage of life may not necessarily develop into asthma, and some children with early-onset asthma will get better with time. 
Therefore, the early prevalence estimates may not accurately reflect the true prevalence of childhood asthma among children with bronchiolitis in infancy. (2) Although some of the studies included in this meta-analysis were adjusted for potential confounding factors, there was still residual confounding affecting the risk estimates in each study and thus pooled estimates in the meta-analysis. Such as tobacco smoke exposure $^{79}$ and genetic determinants, ${ }^{80}$ which have been defined as risk factors for both bronchiolitis and the development of asthma. (3) We used NOS to assess the quality of the enrolled studies. However, it may be controversial because its total scores involve the internal weight of component items. Regardless of whether or not the estimated effect varies with the quality score, investigators can skip the quality score analysis and go directly to the quality component analysis to find out which components are responsible for the variation or avoid the risk of misleading conclusions. Therefore, some researchers consider that the quality score analysis may be redundant. ${ }^{81}$ Moreover, since our meta-analysis included both cohort and case-control studies, there is heterogeneity by study design. Therefore, while NOS evaluation within a group with the same study design would be meaningful, subgroup analysis only with the NOS while ignoring differences in study design may compromise the results. (5) Some data are not presented in the articles and cannot obtained from the original researchers, so we can only use the formula to derive the uncorrected data, which may lead to the deviation of the results. (6) The diagnosis of wheezing/ asthma was not always made by a physician, which might lead to bias; even if the diagnosis was provided by a physician, it was not sure whether the physician was blind to the presence or absence of bronchiolitis before 2 years of age. There is the possibility of reverse causality, including the possibility that there may be misdiagnosis of bronchiolitis that was actually asthma, and equally possible that later asthma is also misdiagnosed. (7) The study by Lin H-W and Lin S- $\mathrm{C}^{34}$ has also shown that infants with bronchiolitis are at increased risk for developing asthma. Excluding this study for statistical reason would not change the overall conclusions but would change the pooled risk estimates. (8) Heterogeneity and possible publication bias should be considered. There was substantial heterogeneity in the pooled data even after subgroup analyses. The considerable amount of heterogeneity may be due to differences in study designs, characteristics of subjects, viral respiratory pathogens, effect estimates reported, confounders and adjustment for confounders. As we also included retrospective casecontrol studies, therefore, heterogeneity may also originate from reporting and recall biases. We just included published studies with sufficient data, so the publication bias might not be completely avoided, even though no statistically significant publication bias was identified.

\section{CONCLUSIONS}

In summary, this meta-analysis indicates that bronchiolitis before 2 years of age may be associated with subsequent development of wheezing/asthma. Assuming the association is causal, early life prevention or treatment of bronchiolitis would be medically important and might play a vital role to decrease the burden of asthma. In view of these limitations, more large-scale prospective studies that fully address potential confounding factors are required to validate the risk identified in the current meta-analysis.

Contributors LL and ZJ developed the study concept. LL, ZJ, GW, ML and DH did the literature search and data extraction. LL, ZJ, ML and SY conducted the statistical analysis. SY and ML revised the manuscript. All authors were involved in drafting and finalising the manuscript.

Funding This work was supported by the National Natural Science Foundation of China (number 81902967) and Key Research and Development Project of Shaanxi Province (number 2020ZDLSF01-06).

Competing interests None declared.

Patient consent for publication Not required.

Provenance and peer review Not commissioned; externally peer reviewed.

Data availability statement Data are available in a public, open access repository. No additional data are available.

Supplemental material This content has been supplied by the author(s). It has not been vetted by BMJ Publishing Group Limited (BMJ) and may not have been peer-reviewed. Any opinions or recommendations discussed are solely those of the author(s) and are not endorsed by BMJ. BMJ disclaims all liability and responsibility arising from any reliance placed on the content. Where the content includes any translated material, BMJ does not warrant the accuracy and reliability of the translations (including but not limited to local regulations, clinical guidelines, terminology, drug names and drug dosages), and is not responsible for any error and/or omissions arising from translation and adaptation or otherwise.

Open access This is an open access article distributed in accordance with the Creative Commons Attribution Non Commercial (CC BY-NC 4.0) license, which permits others to distribute, remix, adapt, build upon this work non-commercially, and license their derivative works on different terms, provided the original work is properly cited, appropriate credit is given, any changes made indicated, and the use is non-commercial. See: http://creativecommons.org/licenses/by-nc/4.0/.

ORCID iD

Lu Liu http://orcid.org/0000-0003-2683-7215

\section{REFERENCES}

1 Asher I, Pearce N. Global burden of asthma among children. Int J Tuberc Lung Dis 2014;18:1269-78.

2 Franco R, Nascimento HF, Cruz AA, et al. The economic impact of severe asthma to low-income families. Allergy 2009;64:478-83.

3 Meng J-F, Rosenwasser LJ. Unraveling the genetic basis of asthma and allergic diseases. Allergy Asthma Immunol Res 2010;2:215-27.

$4 \mathrm{He} \mathrm{Z}$, Wu H, Zhang S, et al. The association between secondhand smoke and childhood asthma: a systematic review and metaanalysis. Pediatr Pulmonol 2020;55:2518-31.

5 Bao Y, Chen Z, Liu E, et al. Risk factors in preschool children for predicting asthma during the preschool age and the early school age: a systematic review and meta-analysis. Curr Allergy Asthma Rep 2017;17:85.

6 Lodge CJ, Tan DJ, Lau MXZ, et al. Breastfeeding and asthma and allergies: a systematic review and meta-analysis. Acta Paediatr 2015;104:38-53. 
7 Gao X, Yin M, Yang P, et al. Effect of exposure to cats and dogs on the risk of asthma and allergic rhinitis: a systematic review and metaanalysis. Am J Rhinol Allergy 2020;34:703-14.

8 Zhang Y, Lin J, Fu W, et al. Mediterranean diet during pregnancy and childhood for asthma in children: a systematic review and meta-analysis of observational studies. Pediatr Pulmonol 2019;54:949-61.

9 Valeriani F, Protano C, Vitali M, et al. Swimming attendance during childhood and development of asthma: meta-analysis. Pediatr Int 2017:59:614-21.

10 Friedman JN, Rieder MJ, Walton JM, et al. Bronchiolitis: recommendations for diagnosis, monitoring and management of children one to 24 months of age. Paediatr Child Health 2014;19:485-91.

11 Brandão HV, Vieira GO, Vieira TO, et al. Acute viral bronchiolitis and risk of asthma in schoolchildren: analysis of a Brazilian newborn cohort. J Pediatr 2017;93:223-9.

12 Lee KK, Hegele RG, Manfreda J, et al. Relationship of early childhood viral exposures to respiratory symptoms, onset of possible asthma and atopy in high risk children: the Canadian asthma primary prevention study. Pediatr Pulmonol 2007;42:290-7.

13 Meissner HC. Viral bronchiolitis in children. N Engl J Med 2016;374:62-72.

14 Smyth RL, Openshaw PJM. Bronchiolitis. Lancet 2006;368:312-22.

15 Sherman CB, Tosteson TD, Tager IB, et al. Early childhood predictors of asthma. Am J Epidemiol 1990;132:83-95.

16 Sims DG, Downham MA, Gardner PS, et al. Study of 8-year-old children with a history of respiratory syncytial virus bronchiolitis in infancy. Br Med J 1978;1:11-14.

17 Murray M, Webb MS, O'Callaghan C, et al. Respiratory status and allergy after bronchiolitis. Arch Dis Child 1992;67:482-7.

18 Balekian DS, Linnemann RW, Hasegawa K, et al. Cohort study of severe bronchiolitis during infancy and risk of asthma by age 5 years. J Allergy Clin Immunol Pract 2017;5:92-6.

19 Régnier SA, Huels J. Association between respiratory syncytial virus hospitalizations in infants and respiratory sequelae: systematic review and meta-analysis. Pediatr Infect Dis J 2013;32:820-6.

20 Liu L, Pan Y, Zhu Y, et al. Association between rhinovirus wheezing illness and the development of childhood asthma: a meta-analysis. BMJ Open 2017;7:e013034.

21 Stang A. Critical evaluation of the Newcastle-Ottawa scale for the assessment of the quality of nonrandomized studies in metaanalyses. Eur J Epidemiol 2010;25:603-5.

22 Zhang J, Yu KF. What's the relative risk? A method of correcting the odds ratio in cohort studies of common outcomes. JAMA 1998;280:1690-1.

23 Tierney JF, Stewart LA, Ghersi D, et al. Practical methods for incorporating summary time-to-event data into meta-analysis. Trials 2007;8:16.

24 McNutt L-A, Wu C, Xue X, et al. Estimating the relative risk in cohort studies and clinical trials of common outcomes. Am J Epidemiol 2003:157:940-3.

25 Greenland S. Model-Based estimation of relative risks and other epidemiologic measures in studies of common outcomes and in case-control studies. Am J Epidemiol 2004;160:301-5.

26 Miettinen O. Estimability and estimation in case-referent studies. Am $J$ Epidemiol 1976;103:226-35.

27 Huedo-Medina TB, Sánchez-Meca J, Marín-Martínez F, et al. Assessing heterogeneity in meta-analysis: $\mathrm{Q}$ statistic or $\mathrm{I} 2$ index? Psychol Methods 2006;11:193-206.

28 J H, S G. Cochrane Handbook for systematic reviews of interventions. John Wiley \& Sons, Ltd, 2008.

29 Sears MR, Greene JM, Willan AR, et al. A longitudinal, populationbased, cohort study of childhood asthma followed to adulthood. $N$ Engl J Med 2003;349:1414-22.

30 McGeachie MJ, Yates KP, Zhou X, et al. Patterns of growth and decline in lung function in persistent childhood asthma. N Engl $J$ Med 2016;374:1842-52.

31 Sousa AW, Barros Cabral AL, Arruda Martins M, et al. Risk factors for fixed airflow obstruction in children and adolescents with asthma: 4-year follow-up. Pediatr Pulmonol 2020;55:591-8.

32 Begg CB, Mazumdar M. Operating characteristics of a RANK correlation test for publication bias. Biometrics 1994;50:1088-101.

33 Egger M, Davey Smith G, Schneider M, et al. Bias in meta-analysis detected by a simple, graphical test. BMJ 1997;315:629-34.

34 Lin H-W, Lin S-C. Environmental factors association between asthma and acute bronchiolitis in young children--a perspective cohort study. Eur J Pediatr 2012;171:1645-50.

35 Backman K, Piippo-Savolainen E, Ollikainen H, et al. Increased asthma risk and impaired quality of life after bronchiolitis or pneumonia in infancy. Pediatr Pulmonol 2014;49:318-25.
36 Backman K, Piippo-Savolainen E, Ollikainen H, et al. Adults face increased asthma risk after infant RSV bronchiolitis and reduced respiratory health-related quality of life after RSV pneumonia. Acta Paediatr 2014:103:850-5.

37 Sigurs N, Aljassim F, Kjellman B, et al. Asthma and allergy patterns over 18 years after severe RSV bronchiolitis in the first year of life. Thorax 2010;65:1045-52.

38 Sigurs N, Bjarnason R, Sigurbergsson F, et al. Respiratory syncytial virus bronchiolitis in infancy is an important risk factor for asthma and allergy at age 7. Am J Respir Crit Care Med 2000;161:1501-7.

39 Sigurs N, Bjarnason R, Sigurbergsson F, et al. Asthma and immunoglobulin $\mathrm{E}$ antibodies after respiratory syncytial virus bronchiolitis: a prospective cohort study with matched controls. Pediatrics 1995;95:500-5.

40 Sigurs N, Gustafsson PM, Bjarnason R, et al. Severe respiratory syncytial virus bronchiolitis in infancy and asthma and allergy at age 13. Am J Respir Crit Care Med 2005:171:137-41.

41 Jung Y-H, Seo J-H, Kim HY, et al. The relationship between asthma and bronchiolitis is modified by TLR4, CD14, and IL-13 polymorphisms. Pediatr Pulmonol 2015;50:8-16.

42 Korppi M, Kuikka L, Reijonen T, et al. Bronchial asthma and hyperreactivity after early childhood bronchiolitis or pneumonia. An 8-year follow-up study. Arch Pediatr Adolesc Med 1994;148:1079-84.

43 Oliveti JF, Kercsmar CM, Redline S. Pre- and perinatal risk factors for asthma in inner City African-American children. Am J Epidemiol 1996:143:570-7.

44 Gold DR, Burge HA, Carey V, et al. Predictors of repeated wheeze in the first year of life: the relative roles of cockroach, birth weight, acute lower respiratory illness, and maternal smoking. Am J Respir Crit Care Med 1999;160:227-36.

45 Ramsey CD, Gold DR, Litonjua AA, et al. Respiratory illnesses in early life and asthma and atopy in childhood. J Allergy Clin Immunol 2007;119:150-6.

46 Larouch V, Rivard G, Deschesnes F, et al. Asthma and airway hyper-responsiveness in adults who required hospital admission for bronchiolitis in early childhood. Respir Med 2000;94:288-94.

47 Schauer U, Hoffjan S, Bittscheidt J, et al. Rsv bronchiolitis and risk of wheeze and allergic sensitisation in the first year of life. Eur Respir $J$ 2002;20:1277-83.

48 Piippo-Savolainen E, Remes S, Kannisto S, et al. Asthma and lung function 20 years after wheezing in infancy: results from a prospective follow-up study. Arch Pediatr Adolesc Med 2004;158:1070-6.

49 Henderson J, Hilliard TN, Sherriff A, et al. Hospitalization for RSV bronchiolitis before 12 months of age and subsequent asthma, atopy and wheeze: a longitudinal birth cohort study. Pediatr Allergy Immunol 2005;16:386-92.

50 Fjaerli H-O, Farstad T, Rød G, et al. Acute bronchiolitis in infancy as risk factor for wheezing and reduced pulmonary function by seven years in Akershus County, Norway. BMC Pediatr 2005;5:31.

51 García-García ML, Calvo C, Casas I, et al. Human metapneumovirus bronchiolitis in infancy is an important risk factor for asthma at age 5 . Pediatr Pulmonol 2007;42:458-64.

52 Mikalsen IB, Halvorsen T, Øymar K. The outcome after severe bronchiolitis is related to gender and virus. Pediatr Allergy Immunol 2012;23:391-8.

53 Midulla F, Pierangeli A, Cangiano G, et al. Rhinovirus bronchiolitis and recurrent wheezing: 1-year follow-up. Eur Respir $J$ 2012;39:396-402.

$54 \mathrm{Kim} \mathrm{BJ}$, Seo JH, Jung YH, et al. Air pollution interacts with past episodes of bronchiolitis in the development of asthma. Allergy 2013;68:517-23.

55 Ruotsalainen M, Hyvärinen MK, Piippo-Savolainen E, et al. Adolescent asthma after rhinovirus and respiratory syncytial virus bronchiolitis. Pediatr Pulmonol 2013;48:633-9.

56 Zomer-Kooijker K, van der Ent CK, Ermers MJJ, et al. Increased risk of wheeze and decreased lung function after respiratory syncytial virus infection. PLoS One 2014;9:e87162.

57 Strickland MJ, Marsh CA, Darrow LA. Gestational age-specific associations between infantile acute bronchiolitis and asthma after age five. Paediatr Perinat Epidemiol 2014;28:521-6.

58 Ardura-Garcia C, Vaca M, Oviedo G, et al. Risk factors for acute asthma in tropical America: a case-control study in the city of Esmeraldas, Ecuador. Pediatr Allergy Immunol 2015;26:423-30.

59 Törmänen S, Lauhkonen E, Riikonen R, et al. Risk factors for asthma after infant bronchiolitis. Allergy 2018;73:916-22.

60 Jeng M-J, Lee Y-S, Tsao P-C, et al. A longitudinal study on early hospitalized airway infections and subsequent childhood asthma. PLoS One 2014;10:e0121906. 
61 Noble V, Murray M, Webb MS, et al. Respiratory status and allergy nine to 10 years after acute bronchiolitis. Arch Dis Child 1997;76:315-9.

62 Riikonen R, Lauhkonen E, Törmänen S, et al. Prospective study confirms that bronchiolitis in early infancy increases the risk of reduced lung function at 10-13 years of age. Acta Paediatr 2019:108:124-30.

63 Chatkin MN, Menezes AMB, Victora CG, et al. High prevalence of asthma in preschool children in southern Brazil: a population-based study. Pediatr Pulmonol 2003;35:296-301.

64 Pereira MU, Sly PD, Pitrez PM, et al. Nonatopic asthma is associated with helminth infections and bronchiolitis in poor children. Eur Respir J 2007;29:1154-60.

65 Lee E, Kwon J-W, Kim H-B, et al. Association Between Antibiotic Exposure, Bronchiolitis, and TLR4 (rs1927911) Polymorphisms in Childhood Asthma. Allergy Asthma Immunol Res 2015;7:167-74.

66 Carroll KN, Wu P, Gebretsadik T, et al. The severity-dependent relationship of infant bronchiolitis on the risk and morbidity of early childhood asthma. J Allergy Clin Immunol 2009;123:1055-61.

67 Lorente F, Laffond E, Moreno E, et al. [Viral infection and asthma: immunologic mechanisms]. Allergol Immunopathol 2001;29:126-33

68 Lotz MT, Peebles RS. Mechanisms of respiratory syncytial virus modulation of airway immune responses. Curr Allergy Asthma Rep 2012;12:380-7.

69 Caixia L, Yang X, Yurong T, et al. Involvement of epigenetic modification in epithelial immune responses during respiratory syncytial virus infection. Microb Pathog 2019;130:186-9.

70 Brandão HV, Vieira GO, Vieira TO, et al. Acute viral bronchiolitis and risk of asthma in schoolchildren: analysis of a Brazilian newborn cohort. J Pediatr 2017:93:223-9.

71 Mansbach JM, Luna PN, Shaw CA, et al. Increased Moraxella and Streptococcus species abundance after severe bronchiolitis is associated with recurrent wheezing. J Allergy Clin Immunol 2020;145:518-27.

72 Guilbert TW, Bacharier LB. Controversies in the treatment of the acutely wheezing infant. Am J Respir Crit Care Med 2011;183:1284-5.

73 Ralston SL, Lieberthal AS, Meissner HC, et al. Clinical practice guideline: the diagnosis, management, and prevention of bronchiolitis. Pediatrics 2014;134:e1474-502.

74 Ricci V, Delgado Nunes V, Murphy MS, et al. Bronchiolitis in children: summary of NICE guidance. BMJ 2015;350:h2305.

75 Scheltema NM, Nibbelke EE, Pouw J, et al. Respiratory syncytial virus prevention and asthma in healthy preterm infants: a randomised controlled trial. Lancet Respir Med 2018;6:257-64.

76 Mochizuki H, Kusuda S, Okada K, et al. Palivizumab prophylaxis in preterm infants and subsequent recurrent wheezing. six-year followup study. Am J Respir Crit Care Med 2017;196:29-38.

77 Prais D, Kaplan E, Klinger G, et al. Short- and long-term pulmonary outcome of Palivizumab in children born extremely prematurely. Chest 2016;149:801-8.

78 O'Brien KL, Chandran A, Weatherholtz R, et al. Efficacy of motavizumab for the prevention of respiratory syncytial virus disease in healthy native American infants: a phase 3 randomised doubleblind placebo-controlled trial. Lancet Infect Dis 2015;15:1398-408.

79 Jones LL, Hashim A, McKeever T, et al. Parental and household smoking and the increased risk of bronchitis, bronchiolitis and other lower respiratory infections in infancy: systematic review and metaanalysis. Respir Res 2011;12:5

80 Thomsen SF, van der Sluis S, Stensballe LG, et al. Exploring the association between severe respiratory syncytial virus infection and asthma: a registry-based twin study. Am J Respir Crit Care Med 2009;179:1091-7.

81 Olkin I. Re: "A critical look at some popular meta-analytic methods". Am J Epidemiol 1994;140:297-9. 